\title{
Pulmonary function test correlation with subclinical respiratory dysfunction in chronic cervical cord compression
}

\author{
Manpreet Singh Banga ${ }^{1}$, Sandeep BV ${ }^{2}$, Anantha Kishan ${ }^{3}$, Rajesh B Devabhakthuni ${ }^{4}$, \\ Arun $\mathrm{MA}^{5}$, Arjun $\mathrm{H} \mathrm{Dev}^{6}$ \\ ${ }^{1,2}$ Assistant Professor, ${ }^{3}$ Professor and Head, ${ }^{4,5,6}$ Post-doctorate Trainee, Department of Neurosurgery, Vydehi Institute \\ of Medical Sciences and Research Centre, Bangalore, India
}

Background: To assess respiratory function in cervical chronic compressive myelopathy (CCM) patients in pre-operative period, post-operative period and to compare pre-operative status with post-operative status. Aims and Objectives: 1 . To assess respiratory function in cervical CCM patients in pre-operative period. 2. To assess respiratory function in cervical CCM patients in post-operative period, following relief of compression. 3. To compare, pre-operative status with post-operative status. Materials and Methods: A prospective study was done in 50 patients with cervical CCM due to either cervical disc disease or ossified posterior longitudinal ligament (OPLL) who were operated. None of the patients included in the study had any clinical signs \& symptoms of respiratory dysfunction. Spirometry was performed in pre-operative and postoperative period after 3 months and results were analyzed. Forced vital capacity (FVC), forced expiratory volume in first second (FEV1), ratio of mean FEV1 to FVC (FEVI: FVC\%) and peak expiratory flow rate (PEFR) were calculated. Results: Majority of the patients were in their fourth decade of life with male predominance. Thirty-six patients $(72 \%)$ presented with prolapsed intervertebral disc and 14 patients (28\%) had ossified posterior longitudinal ligament (OPLL). Patients were operated depending upon the pathology. The present study showed that there was significant reduction in preoperative FVC, FEV1, PEFR values as compared with predicted values and they showed significant improvement in post-operative period after surgical relief of compression. Conclusion: Significant yet occult respiratory dysfunction in form of impairment of various lung capacities exists in patients with cervical CCM. An objective evaluation of this occult respiratory dysfunction is essential to prognosticate, prevent respiratory complications and to improve post-operative respiratory rehabilitation. Institution of incentive spirometry as a routine in all cervical CCM cases will be of benefit in preventing respiratory complications.

Key words: Cervical myelopathy; Spirometry; Respiratory dysfunction
Access this article online

\section{Website:}

http://nepjol.info/index.php/AJMS

DOI: 10.3126/ajms.v12i10.37705

E-ISSN: 2091-0576

P-ISSN: $2467-9100$

Copyright (c) 2021 Asian Journal of Medical Sciences

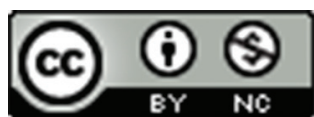

This work is licensed under a Creative Commons Attribution-NonCommercial 4.0 International License.

\section{INTRODUCTION}

Respiratory dysfunction is found to be a major concern after cervical spine trauma contributing to the preoperative and postoperative morbidity associated with the injury. ${ }^{1,2}$ There are well documented reports of incidence of respiratory complications post-acute spinal cord injury, however, evidence of such respiratory impairment in the context of cervical chronic compressive myelopathy (CCM) is inadequate. ${ }^{1}$ One of the reasons might be the subtlety and the lack of overt signs of respiratory dysfunction in these patients. ${ }^{3,4}$ Despite the subclinical nature of respiratory dysfunction preoperatively, these patients are at risk of respiratory complications like atelectasis and pneumonia postoperatively, which plays an important role in the prognosis. Therefore, it is imperative to assess 
these patients and document the presence of subclinical respiratory dysfunction. ${ }^{4}$

Pulmonary function tests are simple, readily available and valuable investigations in the detection and subsequent follow-up of patients with respiratory abnormalities preoperatively. Spirometry is the most frequently used method to measure pulmonary function. Routinely assessed variables are forced vital capacity (FVC), peak expiratory flow rate (PEFR), forced expiratory volume by the end of first second (FEV1), ratio of mean FEV1 to FVC (FEV1: FVC) and percentage of the predicted for each of the values depending on the age and height. ${ }^{5}$

Calculation of FEV1/FVC differentiates the restrictive respiratory abnormality from obstructive diseases. A FEV1/FVC ratio $<70 \%$ of the predicted implying normal inspiratory capacity but obstruction to the expiratory phase is seen in obstructive pathologies like chronic obstructive pulmonary disease (COPD) and asthma. A FEV1/FVC ratio $>70 \%$, where both FEV1 and FVC are reduced, but the reduction of FVC being more compared to FEV1, is seen in restrictive pathologies such as pulmonary fibrosis, neuromuscular and chest wall deformities. ${ }^{5}$ The respiratory abnormality that is associated with cervical CCM is a type of restrictive lung disease. $^{6}$

\section{Aims and objectives}

1. To assess respiratory function in cervical CCM patients in pre-operative period.

2. To assess respiratory function in cervical CCM patients in post-operative period, following relief of compression.

3. To compare, pre-operative status with post-operative status.

\section{MATERIALS AND METHODS}

A prospective cohort study was done in a sample population of 50 patients with cervical CCM due to either cervical disc disease or ossified posterior longitudinal ligament (OPLL) who were operated at our institution, Vydehi Institute of Medical Sciences and Research Centre, Bangalore. Presence of any symptoms pointing to respiratory dysfunction was noted and thorough physical examination was carried out. Spirometry was performed in pre-operative period after clinical and radiological diagnosis and postoperatively after 3 months and results were analysed. Preoperative and postoperative FEV1, FVC, FEV1/FVC and PEFR values were noted. The study was pre-approved by the Institutional Ethical Committee.
Inclusion criteria

Patients diagnosed of cervical CCM due to cervical disc disease or OPLL and scheduled for surgery.

\section{Exclusion criteria}

1. Patients with acute traumatic cervical spine injury.

2. Chronic smokers.

3. Patients with chronic pulmonary disorders like asthma and chronic obstructive pulmonary disease.

4. Pre-existing cardiac disease.

5. Patients not consenting for study.

\section{Statistical methods}

Descriptive statistics were calculated for each parameter and reported. The mean preoperative vs predicted values with respect to age and height were compared with student $\mathrm{t}$ test. The mean postoperative vs predicted values also were compared using student t-test with $P<0.05$ taken as statistical significance. The data was analysed using statistical software SPSS version 15.0.

\section{RESULTS}

\section{Age distribution}

Majority of the patients were in their fourth decade of life (Table 1).

\section{Gender distribution}

Males were predominant $(88 \%)$ in the present study (Table 2).

\section{Pathology}

Thirty-six patients $(72 \%)$ presented with prolapsed intervertebral disc. Fourteen patients $(28 \%$ ) had Ossification of the posterior longitudinal ligament (OPLL) as the pathology.

\section{Type of surgery}

Anterior approach and discectomy were performed for 28 patients (56\%). Corpectomy with fusion was performed

\begin{tabular}{lcc} 
Table 1: Age distribution of the patients \\
\hline Age & Frequency & Percent \\
\hline 31 to 40 & 6 & 12.0 \\
41 to 50 & 24 & 48.0 \\
$>=51$ & 20 & 40.0 \\
Total & 50 & 100.0 \\
\hline
\end{tabular}

\begin{tabular}{lcc} 
Table 2: Gender Distribution of the patients \\
\hline Gender & Frequency & Percentage \\
\hline Male & 44 & 88.0 \\
Female & 06 & 12.0 \\
Total & 50 & 100.0 \\
\hline
\end{tabular}


Table 3: Forced Vital Capacity

\begin{tabular}{lccc} 
FVC (Litre) & Mean +/- SD (Min - Max.) & Significance from predicted & $\begin{array}{c}\text { Significance from } \\
\text { pre-operative }\end{array}$ \\
\hline Predicted & $3.4456+/-0.4749(2.5900-4.1800)$ & - & \\
Preoperative & $2.869+/-0.474(2.080-3.780)$ & 0.01 & $<0.001$ \\
Postoperative & $3.1112+/-0.4771(2.1800-3.9700)$ & 0.01 & \\
\hline
\end{tabular}

\begin{tabular}{lccc} 
Table 4: Forced Expiratory Volume in first second & \\
\hline FEV1 (Litre) & Mean+/- SD (Min. - Max.) & Significance from predicted & $\begin{array}{c}\text { Significance from } \\
\text { pre-operative }\end{array}$ \\
\hline Predicted & $3.009+/-.386(1.990-3.560)$ & - & $<01$ \\
Preoperative & $2.626+/-.364(1.690-3.180)$ & 0.001 & $<0.001$ \\
Postoperative & $2.7232+/-.3421(1.9400-3.2400)$ & 0.001 & \\
\hline
\end{tabular}

\begin{tabular}{lccc}
\multicolumn{4}{l}{ Table 5: Ratio of Mean FEV1 to FVC (FEV1: FVC \%) } \\
\hline FEV1: FVC & Mean+/- SD (Min. - Max.) & Significance from predicted (P value) & $\begin{array}{c}\text { Significance from } \\
\text { pre-operative }\end{array}$ \\
\hline Predicted & $88.268+/-14.069(61.419-122.491)$ & - & \\
Preoperative & $93.168+/-18.21458 .4775-138.557)$ & 0.023 & $<0.001$ \\
Postoperative & $88.564+/-16.1682(63.816-138.073)$ & 0.715 & \\
\hline
\end{tabular}

for 12 patients (24\%). Rest of the patients (20\%) underwent decompressive laminectomy.

\section{Analysis of pulmonary function tests parameters Forced vital capacity (FVC)}

There was significantly lower FVC values in the study population as compared with predicted values. Postoperatively, when compared to pre-operative values there was significant improvement but it was not up to the predicted values (Table 3 ).

Forced expiratory volume in first second (fev1)

There was a significant reduction in the preoperative FEV1 values as compared with predicted values. There was significant improvement in post-operative FEV1 values but as with FVC, post-operative FEV1 values were not up to the predicted values (Table 4).

\section{Ratio of mean FEV1 to FVC (FEV1: FVC \%)}

There was significantly higher preoperative FEV1: FVC ratio as compared with predicted value. As reduction in FEV1 is proportionately less than reduction in FVC, this value appears increased. Postoperatively, values of FEV1 \& FVC individually are higher than pre-operative period, however, increase in FEV1 is relatively low compared to FVC hence ratio has come down (Table 5 and 6).

\section{Peak expiratory flow rate (PEFR)}

Significantly lower preoperative PEFR was found as compared with predicted values. There was slight improvement in the postoperative values compared to preoperative PEFR but remained significantly lower than the predicted values (Table 7).

\begin{tabular}{lccc}
\multicolumn{4}{l}{ Table 6: FEV1: FVC \% } \\
\hline Parameters & Predicted & Pre-OP Mean & Post-OP Mean \\
\hline FEVI (L) & 3.00 & 2.626 & 2.72 \\
FVC (L) & 3.44 & 2.869 & 3.11 \\
FEVI/FVC (\%) & $87.9 \%$ & $93 \%$ & $88.5 \%$ \\
\hline
\end{tabular}

\section{DISCUSSION}

Respiratory dysfunction is a known complication post cervical spinal cord injury. But in patients with Craniovertebral junction anomalies and other compressive cervical lesions occult chronic respiratory dysfunction exists. ${ }^{7,8}$ Vital capacity is the maximum amount of air that can be exhaled after deep inspiration. It is influenced by the lung compliance, chest wall compliance and also by the action of respiratory muscles. The primary muscles aiding inspiration are diaphragm and external intercostal, innervated by the phrenic nerve (C3-C5) and intercostal nerves arising from thoracic spinal nerves respectively. Injury to the spinal cord above the $\mathrm{C} 5$ level results in interruption of impulse transmission to diaphragm as well as intercostal muscles. This leads to decrease in the inspiratory lung volumes and capacities. ${ }^{9}$ In cervical CCM, compression of the anterior nerve roots of C5-T1 might contribute to the decreased lung volumes as described. A mild stress as a consequence of the chronic compression of the cervical cord and plasticity of the respiratory pathways also might contribute. ${ }^{1}$ Nonetheless, the precise mechanism of the subclinical respiratory impairment seen in CCM is not known. ${ }^{4}$

In our study none of the patients had any prior comorbidities or symptomatic respiratory dysfunction preoperatively. 


\begin{tabular}{|c|c|c|c|}
\hline PEFR- L/Min & Mean+/- SD (Min. - Max.) & Significance from predicted & $\begin{array}{l}\text { Significance from } \\
\text { pre-operative }\end{array}$ \\
\hline Predicted & $7.867+/-.578(6.020-8.670)$ & - & \\
\hline Preoperative & $5.8200+/-.7194(4.2300-7.6200)$ & $<0.001$ & \\
\hline Postoperative & $6.0784+/-.6750(4.9800-7.8400)$ & $<0.001$ & $<0.001$ \\
\hline
\end{tabular}

Majority of them were in their fourth decade of life. Males were predominant $(88 \%)$ in our study. Prolapsed intervertebral disc was the major pathology followed by OPLL. Majority of patients underwent anterior approach and discectomy. There were significantly lower lung volumes (FEVI and FVC) in patients with cervical CCM with slight improvement after 3 months postoperatively but still significantly lower than the predicted values. The FEV1/FVC ratio was substantially higher preoperatively with marked reduction almost equal to the ratio predicted for the given age and height at the 3 month follow up.

In accordance with our study, a Japanese study ${ }^{10}$ reported marked improvement in the tidal volumes in patients with cervical spondylitic myelopathy 6 months after laminoplasty and also improvement in the Japanese Orthopaedic Association scores (JOA) and Neurosurgical Cervical Spine Scale scores (NCSS). They opined that measurement of lung volumes might serve as an estimate of spinal cord function. Another study by Toyoda et al., ${ }^{4}$ in the year 2004 confirmed the presence of subclinical respiratory dysfunction in cervical CCM cases. As in our study, they reported lower PEFR values in these patients. They attributed the mechanism of respiratory impairment to the damage of respiratory tracts as a result of chronic compression and the subsequent compensatory reaction to preserve the respiratory system.

Yoshida G et al.,11 in 2011 concluded that elderly patients with cervical CCM have a decreased percentage of vital capacity $(\% \mathrm{VC})$ and high risk of cardiopulmonary complications. Timely decompression if performed avoid cardiopulmonary dysfunction in peri-operative period.

A recent Indian study by Bhagavathula ID et al., ${ }^{1}$ described the lower FEV1, FVC and maximal voluntary ventilation (MVV) values in patients with CCM compared to the control population confirming the presence of respiratory impairment in these patients. They also found that the FVC was significantly improved postoperatively compared to the preoperative value but yet remains lower compared to the control group. Conversely, the FEV1 and FEV1/ FVC did not change much postoperatively from the preoperative values. In our study all the parameters analysed had significant improvement in the post-operative period.

No other study except Bhagavathula et al., ${ }^{1}$ has studied ratio of FEV1to FVC. They compared the mean post-operative ratio with controls and found no significant difference from the control values $(p=0.204)$. However, in our study we had no controls and the ratio of FEV1 to FVC showed significant improvement in post-operative period when compared to pre-operative values. Ishibe et al., also reported lower preoperative FVC in patients with lesions more cranially or in patients with multilevel lesions which showed substantial improvement postoperatively which supports our observation in this regard.

Nishida T et al., ${ }^{12}$ in 2018 reported similar findings in a female patient who had OPLL with myelopathic features. They studied the pre-operative FVC, FEV1 and FEV1: FVC. They found significant derangement of the above parameters and compared these parameters after performing C3-C7 laminoplasty. They found significant improvement in her percentage of vital capacity ( $\% \mathrm{VC})$ and other parameters studied in pre-operative period.

The present study showed that there was significant reduction in preoperative FVC, FEV1, PEFR values as compared with the predicted values. This suggested a significant occult respiratory dysfunction in these patients as none of them had any clinical signs \& symptoms preoperatively. On the other hand, significant improvement was seen in the pulmonary function tests at the 3 months follow up after surgical relief of compression. This could be attributed to a gradual reversal of compressive effects on descending motor pathways which also improve diaphragmatic and respiratory muscle function. ${ }^{13}$ The knowledge about preoperative occult respiratory dysfunction enabled us to institute preoperative incentive spirometry and other measures as needed in future patients.

\section{CONCLUSION}

Significant yet occult respiratory abnormality in the form of restrictive pattern of pulmonary function tests prevails in patients with cervical CCM even in the absence of overt clinical respiratory distress. Henceforth, detection of this subclinical respiratory dysfunction is necessary to prognosticate, to avoid respiratory complications and also to mend the postoperative respiratory function. Institution of incentive spirometry as a routine in all cervical CCM cases will be of benefit in preventing respiratory complications. 


\section{REFERENCES}

1. Bhagavatula ID, Bhat DI, Sasidharan GM, Mishra RK, Maste PS, Vilanilam GC, et al. Subclinical respiratory dysfunction in chronic cervical cord compression: a pulmonary function test correlation. Neurosurg Focus. 2016; 40: 1-6.

https://doi.org/10.3171/2016.3.FOCUS1647

2. Ball PA. Critical care of spinal cord injury. Spine. 2001; 26: $27-30$.

https://doi.org/10.1097/00007632-200112151-00006

3. Nomura T, Tani T, Kitaoka K, Enoki H and Ishida K. A subclinical impairment of ventilatory function in cervical spondylotic myelopathy. Arch Phys Med Rehabil. 2004; 85: 1210-1211. https://doi.org/10.1016/j.apmr.2003.10.011

4. Toyoda H, Nakamura H, Konishi S, Terai H and Takaoka K. Does chronic cervical myelopathy affect respiratory function? J Neurosurg Spine. 2004; 1: 175-178.

https://doi.org/10.3171/spi.2004.1.2.0175

5. Ranu $\mathrm{H}$, Wilde $\mathrm{M}$ and Madden $\mathrm{B}$. Pulmonary Function tests. Ulster Med J. 2011; 80: 84-90. PMCID: PMC3229853

6. Fahad EH, Hashim ZH and Nema IS. Cervical Spinal Stenosis and Risk of Pulmonary Dysfunction: Case Control Study. International journal of critical illness and injury science. 2020; 10:16-19.

https://doi.org/10.4103/IJCIIS.IJCIIS_83_19

7. Rosomoff HL. Occult respiratory and autonomic dysfunction in craniovertebral anomalies and upper cervical spinal disease. Spine. 1986; 11:345-347. https://doi.org/10.1097/00007632-198605000-00010

8. Rath GP, Bithal PK, Guleria R, Chaturvedi A, Kale SS, Gupta V, et al. A comparative study between preoperative and postoperative pulmonary functions and diaphragmatic movements in congenital craniovertebral junction anomalies. J Neurosurg Anesthesiol. 2006; 18: 256-261. https://doi.org/10.1097/00008506-200610000-00007

9. Ishibe T and Takahashi S. Respiratory dysfunction in patients with chronic-onset cervical myelopathy. Spine. 2002; 27: 2234-2239. https://doi.org/10.1097/00007632-200210150-00010

10. Yanaka K, Noguchi S, Asakawa H and Nose T. Laminoplasty improves respiratory function in elderly patients with cervical spondylotic myelopathy. Neurol Med Chir (Tokyo). 2001; 41: 488-493.

https://doi.org/10.2176/nmc.41.488

11. Yoshida G, Kanemura T, Ishikawa $Y$, Sakai $Y$, Iwase $T$, Matsuyama $Y$, et al. Cardiopulmonary function in elderly patients with cervical spondylotic myelopathy. J Orthop Sci. 2012; 17:3-8. https://doi.org/10.1007/s00776-011-0178-4

12. Nishida T, Ishiguro T, Ota C, Takaku Y, Kagiyma N, Karushima K, et al. Restrictive ventilatory impairment improved by laminoplasty for ossification of the posterior longitudinal ligament. Clin Case Rep. 2019; 7: 284-288. https://doi.org/10.1002/ccr3.1959

13. Uppar AM, Vilanilam GC, Devi BI, Bhat DI, Shukla DP, Siroya H, et al. Respiratory Dysfunction in Craniovertebral Junction Pathology: A Pulmonary Function Test Correlation. J Spinal Surg. 2017; 4:164-170. https://doi.org/10.5005/jp-journals-10039-1152

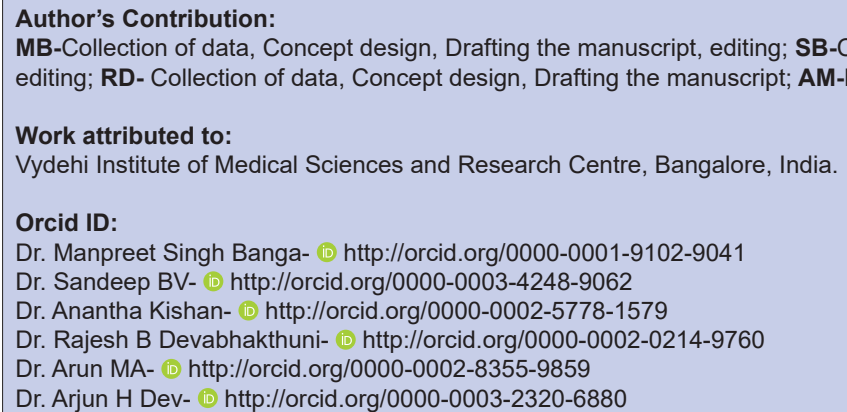

